\title{
ASYSTEMATIC APPROACH TO MULTI-PERIOD STRESS TESTING OF PORTFOLIO CREDIT RISK
}

Thomas Breuer, Martin Jandačka. Javier Mencia and Martin summer

Documentos de Trabajo N. 1018

\section{baN DO DE ESPANAa}
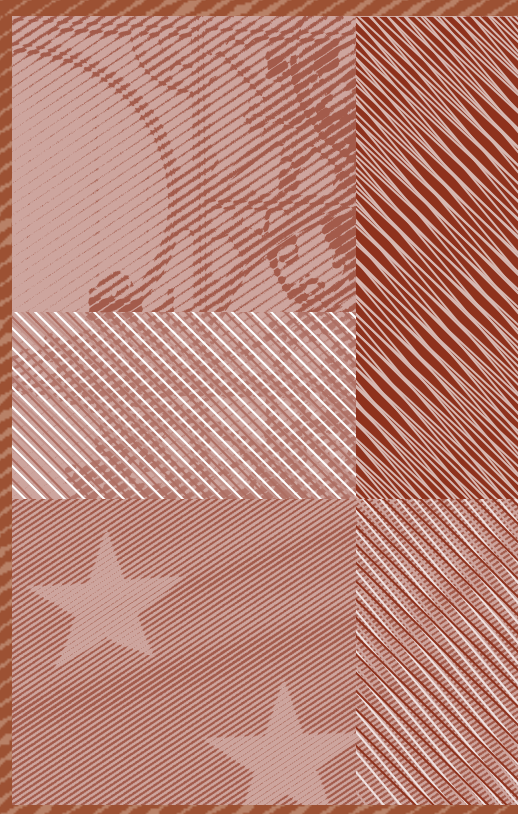
A SYSTEMATIC APPROACH TO MULTI-PERIOD STRESS TESTING OF PORTFOLIO

CREDIT RISK 


\title{
A SYSTEMATIC APPROACH TO MULTI-PERIOD STRESS TESTING OF PORTFOLIO CREDIT RISK(*)
}

\author{
Thomas Breuer and Martin Jandačka \\ RESEARCH CENTRE PPE \\ Javier Mencía \\ BANCO DE ESPAÑA
}

Martin Summer

OESTERREICHISCHE NATIONALBANK

(*) Thomas Breuer and Martin Jandačka, Research Centre PPE, Fachhochschule Vorarlberg, Hochschulstr. 1 A-6850 Dornbirn, Austria. Javier Mencía, Financial Stability Department, Banco de España, Alcalá, 48, 28014 Madrid, Martin Summer, Oesterreichische Nationalbank, Otto Wagner Platz 3, A-1090 Vienna, Austria. The views expressed in this paper are those of the authors, and may not necessarily coincide with those of their institutions. We are grateful for valuable comments and suggestions from an anonymous referee of the working paper series of the Banco de España. Of course, we are responsible for any remaining errors. Corresponding author: martin. summer(at)oenb.at. 
The Working Paper Series seeks to disseminate original research in economics and finance. All papers have been anonymously refereed. By publishing these papers, the Banco de España aims to contribute to economic analysis and, in particular, to knowledge of the Spanish economy and its international environment.

The opinions and analyses in the Working Paper Series are the responsibility of the authors and, therefore, do not necessarily coincide with those of the Banco de España or the Eurosystem.

The Banco de España disseminates its main reports and most of its publications via the INTERNET at the following website: http://www.bde.es.

Reproduction for educational and non-commercial purposes is permitted provided that the source is acknowledged.

() BANCO DE ESPAÑA, Madrid, 2010

ISSN: 0213-2710 (print)

ISSN: 1579-8666 (on line)

Depósito legal: M. 28654-2010

Unidad de Publicaciones, Banco de España 


\section{Abstract}

We propose a new method for analysing multiperiod stress scenarios for portfolio credit risk more systematically than in the current practice of macro stress testing. Our method quantifies the plausibility of scenarios by considering the distance of the stress scenario from an average scenario. For a given level of plausibility our method searches systematically for the most adverse scenario for the given portfolio. This method therefore gives a formal criterion for judging the plausibility of scenarios and it makes sure that no plausible scenario will be missed. We show how this method can be applied to a range of models already in use among stress testing practitioners. While worst case search requires numerical optimisation we show that for practically relevant cases we can work with reasonably good linear approximations to the portfolio loss function that make the method computationally very efficient and easy to implement. Applying our approach to data from the Spanish loan register and using a portfolio credit risk model we show that, compared to standard stress test procedures, our method identifies more harmful scenarios that are equally plausible.

Keywords: Stress Testing, Credit Risk, Worst Case Search, Maximum Loss.

JEL classification: G28, G32, G20, C15. 


\section{Introduction}

When supervisory authorities or financial institutions are asked to produce stress tests for particular aggregate or individual portfolios they face a basic challenge: While scenarios should be extreme they should at the same time also be plausible. Clearly the more extreme the scenarios which are considered the less plausible they become: There is a trade off between severity and plausibility of stress scenarios. Once this trade off has been made and some measure and level of plausibility have been determined we still have to make sure not to ignore any severe scenario for a given plausibility. Unfortunately, current stress test procedures generally use a few hand-picked scenarios. This makes stress testing subject to considerable arbitrariness. If, for which reason whatsoever, an institution does not pick the worst scenarios but just some scenarios involving large risk factor moves it might get or give an illusion of safety. There is, therefore, a real danger that 'stress testing results will continue to lull users into a false sense of security' (Borio and Drehmann [2009]). Furthermore, current stress test procedures do neither allow for making a trade off between plausibility and severity in a systematic and transparent way, nor do they lead to direct and specific suggestions for risk reducing actions.

In this paper we offer a systematic approach to stress testing. We specify a measure of plausibility based on the Mahalanobis distance of the changes in a set of factors. In this way, we can control how far we go into the tails of the risk factor distribution in our search for stress scenarios. All scenarios above the minimal level of plausibility are considered on an equal footing, all scenarios under the minimal plausibility level are left out of consideration. This makes transparent the trade off between plausibility and severity one always has to make. Then, we determine the worst case by maximising a loss function among all scenarios above the minimal level of plausibility. If an institution can take this worst case loss it can be sure to survive any scenario at this level of plausibility. At the same time our method allows for an analysis of appropriate risk reducing actions.

While the theory and the concepts of worst case search have already been developed in a one-period framework by Breuer et al. [2009], the current paper introduces two major novel contributions. First, we extend the method to a multi-period setting, in which scenarios are paths of macroeconomic variable values rather than values at one point in time. Second, we show the practical usefulness of this approach by means of a meaningful and relevant empirical application, which makes use of standard data and models already in use by stress testing practitioners. Given is a portfolio and some statistical model for the risk factors that influence the values of positions and thus the portfolio value at a given future time horizon. The uncertainty about the realization of risk factors is described by a risk factor distribution that is estimated from historical data. For a loan portfolio these risk factors will include the macroeconomic environment (because of its impact on the payment ability and thus on the solvency of borrowers), market factors like interest rates or exchange rates but also idiosyncratic factors that influence a borrower's solvency. We use loan register data from the central loan register of the Banco de España and a credit risk stress testing model developed by Jiménez and Mencía [2009]. Similar credit risk portfolio models have been used by practitioners in many other central banks. In fact, portfolio credit risk models with similar characteristics 
have been estimated using data from Canada [Misina et al., 2006], Finland [Virolainen, 2004], Hong Kong [Wong et al., 2008], Italy [Fiori et al., 2007] or the U.K. [Drehmann, 2005, Drehmann et al., 2006]. An international model can also be found in Pesaran et al. [2006]. These models follow Wilson [1997a,b] in trying to model the default frequencies of loans to different economic sectors as functions of macroeconomic conditions. Compared to the previous literature, Jiménez and Mencía [2009] contain two important novel features. First, they not only consider corporate loans but also loans to households such as mortgages and consumption loans. Second, they introduce latent factors in order to model the correlations between different types of loans. However, since the methodology is otherwise consistent with the previous literature, the stress testing approach that we use can be directly applied to other countries. In this sense, we demonstrate that the application to real world stress testing problems is straightforward and does not raise complicated implementation issues.

We believe that our approach is able to address some of the more recent criticism raised against stress testing. Alfaro and Drehmann [2009], for instance, criticized the realism of using mainly domestic macroeconomic factors in the description of stress scenarios. They question the ability to construct plausible yet severe scenarios and they diagnose a lack of robustness of models during a crisis. While our method is agnostic with respect to which are the relevant risk factors, our model shows a way how plausible and severe scenarios can be constructed. In our example we see that our method of worst case search applied during the boom year 2006 was clearly superior to historical scenario stress testing in gauging the subsequent crisis. While we use the historical data to delineate the plausibility of the stress scenario the worst case looks clearly different from the historical recession scenario and comes much nearer to the actual downturn that materialized in 2008. Hence, we show that worst case search could have generated scenarios as severe as the current crisis based only on information prior to 2007. Notice, though, that we do not mean to imply that our model would have predicted the crisis, but rather that its use could have forewarned practitioners that such an unprecedented scenario could occur within reasonable levels of plausibility.

Stress testing and risk measurement models have also been criticised for assuming naively that the risk factor distribution in times of crisis is the same as always. Here we do not systematically address this robustness issue. New results by Breuer and Csiszár [2010] generalize our approach to address this question. In this more general framework questions of parameter stability and model risk can be directly analysed.

Alfaro and Drehmann [2009] conclude that the unsatisfactory state of stress testing models calls for a stronger role of judgement in stress testing. Our approach is open to this requirement. While Alfaro and Drehmann [2009] want to more strongly weight judgement with respect to the output of a stress test, our approach would argue to the contrary that the judgement should enter more strongly on the the side of the input. We propose to pin down ex ante in a transparent way the plausibility one is willing to consider and then accept the result of the stress test. The advantage we see in this approach is that the current practice and the practice augmented with stronger judgement as suggested in Alfaro and Drehmann [2009] makes stress testing an exercise extremely prone to all kinds of manipulation. We believe that our approach is a step towards manipulation proofness of stress testing. As such our paper contributes not only 
to the methodology of stress testing but has wider implications for the political economy of stress testing.

The paper is organized as follows. Section 2 shows how the worst case search can be applied to a set up where risk factor movements are forecasted over multiple time steps. Section 3 describes our data of the Spanish loan market. Section 4 describes and discusses our main results and Section 5 concludes.

\section{Worst Case Search and Credit Risk}

\subsection{To which Credit Risk Models Can Worst Case Search be Applied?}

We want to apply the method of worst case search over risk factor domains of certain plausibility to the analysis of portfolio credit risk. In order to do so we need to be able at each point in time $t$ to measure the expected loss of position $i$ in sector $k$, for $k=1, \cdots, K$. We need a model structure that can express the expected loss as a function of risk factors. Typically these risk factors are innovations of macroeconomic variables at future times, as well as idiosyncratic events. We write these categories of risk factors separately as two vectors $\boldsymbol{u}_{i}$ and $\boldsymbol{v}$, with $\boldsymbol{v}$ describing the innovations of macroeconomic variables at different future times.

At a given time $t$ the loss of a position $i$ is given by $L_{i, t}\left(\boldsymbol{u}_{i}, \boldsymbol{v}\right)$. In typical stress tests we are interested in assessing what happens to the portfolio loss given the path followed by the macroeconomic risk factors. This involves taking expectations over the idiosyncratic factors. Thus we are interested in the expected loss at a given time $t$ for a certain horizon (say $m$ periods) given a future scenario path of macroeconomic risk factors $\boldsymbol{v}$ and the information $I_{t}$ available at $t$ :

$$
\mathbb{E}\left[\sum_{s=t+1}^{t+m} \sum_{i} L_{i, s}\left(\boldsymbol{u}_{i}, \boldsymbol{v}\right) \mid I_{t}, \boldsymbol{v}\right] .
$$

In a specific application of course $L_{i, t}\left(\boldsymbol{u}_{i}, \boldsymbol{v}\right)$ is determined by the credit risk model. The main assumption we need for our macroeconomic stress test method is that the stressed macro risk factors $\boldsymbol{v}$ are elliptically distributed. (The more general method in Breuer and Csiszár [2010] works for arbitrary risk factor distributions.) Let us see how (1) looks like in some familiar credit risk models, and in the model we use.

Example 1: Gaussian Single Factor Model This model, which was developed by Vasicek [1987], Finger [1999] and Gordy [2003] among others, approximates the loss distribution of a credit portfolio in which dependence between defaults is driven by a single common latent factor. The default of an obligor $i$ from the class $k(i)$ is driven by an auxiliary stochastic variable $z_{i, t}$. This variable is parametrized as

$$
z_{i, t}=\beta_{k} v_{t}+\sqrt{1-\beta_{k}^{2}} u_{i, t}
$$

where $v_{t}$ represents a latent macroeconomic factor, $u_{i, t}$ is an independent idiosyncratic risk term and $\beta_{k} \in(-1,1)$ captures the sensitivity of $z_{i, t}$ to the macroeconomic factor. Both $v_{t}$ and $u_{i, t}$ are modeled as standard normal variates 
so that $z_{i, t}$ is also standard normal. The intuition behind this approach is that $z_{i, t}$ reflects the value of the firm. The obligor defaults when this value decreases below a given boundary $\psi_{i}$. Hence, the loss function can be expressed as

$$
L_{i, t}\left(\boldsymbol{u}_{i, t}, v_{t}\right)=1\left(z_{i, t}<\psi_{i}\right) L G D_{i} E A D_{i},
$$

where $1(\cdot)$ is the usual indicator function, while the loss given default $\left(L G D_{i}\right)$ and the exposure at default $\left(E A D_{i}\right)$ are assumed to be known non-stochastic quantities. Assuming that default rates are homogeneous in each rating class (same $\beta_{k}$ and $\psi_{i}$ for obligors $i$ in the same class $\left.k(i)\right)$ the expected loss (1) becomes

$$
\sum_{s=t+1}^{t+m} \sum_{i} \Phi\left(\frac{\psi_{i}-\beta_{k} v_{s}}{\sqrt{1-\beta_{k}^{2}}}\right) L G D_{i} E A D_{i},
$$

where $\Phi(\cdot)$ denotes the standard normal cumulative distribution function (cdf). The assumption of homogeneous default rates within classes can be easily relaxed.

Example 2: Firm Value Model This model, due to Merton [1974], uses option pricing theory to value debt. Although it was originally developed in continuous time, we will use its discretized version to remain consistent with the rest of the paper. Consider a firm $i$ whose assets are worth $A_{i, t}$ at $t$. In this simple context, firms issue debt as zero-coupon bonds with face values $D_{i}$ and maturities at $t+m$. Due to limited liability, the equity owners of each firm will pay $D_{i}$ only if the value of the firm at maturity is greater than its debt, i.e. $A_{i, t+m}>D_{i}$. In any other case, the lender will obtain the residual value of the firm at maturity. Hence, the loss at $t+m$ can be expressed as

$$
\begin{aligned}
L_{i, t+m}\left(A_{i, t+m}\right) & =\max \left\{D_{i}-A_{i, t+m}, 0\right\} \\
& =\max \left\{A_{i, t+m}-D_{i}, 0\right\}-\left(A_{i, t+m}-D_{i}\right)
\end{aligned}
$$

Notice that the evolution of the firms' asset values from $t$ to $t+m$ may depend on a set of idiosyncratic and macroeconomic shocks that occur during this period. Hence, the expected loss (1) given $I_{t}$ and a scenario path of macroeconomic shocks $\boldsymbol{v}=\left(\boldsymbol{v}_{t+1}^{\prime}, \cdots, \boldsymbol{v}_{t+m}^{\prime}\right)^{\prime}$ can be expressed as

$$
\begin{aligned}
\mathbb{E}\left[L_{i, t+m}\left(A_{i, t+m}\right) \mid I_{t}, \boldsymbol{v}\right]= & c_{t}\left(t+m, D_{i}, \boldsymbol{v}\right) \\
& -\mathbb{E}\left[A_{i, t+m} \mid I_{t}, \boldsymbol{v}\right]+D_{i},
\end{aligned}
$$

where $c_{t}\left(t+m, D_{i}, \boldsymbol{v}\right)$ denotes the price at $t$ of a European call option on the firm's asset value with strike $D_{i}$ and expiration at $t+m$, given $I_{t}$ and the evolution of the macroeconomic factors. This price will correspond to the well known formula of Black and Scholes [1973] if the firms' values are modeled as geometric Brownian motions.

The Jiménez-Mencía Model In our application we use a version of the credit risk model developed by Jiménez and Mencía [2009]. In line with similar models that have been developed in other central banks, this model is a multifactor extension of Example 1 that allows for several macroeconomic factors to affect the loss distribution. In addition, it introduces time series dynamics 
to capture the high persistence of actual default rates, see Fig. 3. The model addresses only credit risk of domestic loan portfolios. Other possible sources of bank crises such as shocks to foreign assets or liquidity problems are not modelled.

The loan portfolio is partitioned into $K$ sectors. The losses due to loan $i$ from sector $k$ are decomposed in any period $t$ as

$$
L_{i, t}=D_{i, t} \cdot L G D_{k} \cdot E A D_{i}
$$

if LGD are homogeneous within sectors. In this equation $D_{i, t}$ is a default indicator. It is a binary variable that equals 1 in case of default and 0 otherwise. $E A D_{i}$ is the exposure of obligor $i$ at default.

We assume that the probability of default is homogeneous within each sector and write it as

$$
\operatorname{Pr}\left(D_{i, t}=1\right)=\pi_{k, t} .
$$

We describe this variable with a probit model

$$
\pi_{k, t}=\Phi\left(z_{k, t}\right)
$$

where

$$
z_{k, t}=\alpha_{k}+\rho_{k} z_{k, t-1}+\sum_{j=1}^{q} \gamma_{k, j} \cdot \Delta \boldsymbol{x}_{t-j}+\beta_{k} f_{t}+u_{k, t},
$$

$\Phi(\cdot)$ is the cdf of the standard normal distribution, $\Delta \boldsymbol{x}_{t}=\boldsymbol{x}_{t}-\boldsymbol{x}_{t-1}$ is a vector of quarterly changes in (observable) macroeconomic variables, $f_{t}$ is a common latent factor and $u_{k t}$ is an idiosyncratic error term for sector $k$. This probit model can be justified by applying to the same arguments as in the single factor model of Example 1. This is why the probability of default can be expressed as a standard normal cdf transform of a Gaussian variable in both cases. However, we introduce time series dynamics in (8) and allow for more than one factor. Furthermore, the macrovariables follow a diagonal AR(1) process

$$
\Delta \boldsymbol{x}_{t}=A_{0}+A_{1} \Delta \boldsymbol{x}_{t-1}+\boldsymbol{v}_{t}
$$

with

$$
A_{0}=\left[\begin{array}{l}
a_{01} \\
a_{02}
\end{array}\right]
$$

and

$$
A_{1}=\left[\begin{array}{cc}
a_{11} & 0 \\
0 & a_{12}
\end{array}\right]
$$

The error terms $\boldsymbol{v}_{t} \sim$ iid $N(0, \boldsymbol{\Sigma}), f_{t} \sim$ iid $N(0,1)$ and $u_{k, t} \sim$ iid $N\left(0, \sigma_{k}^{2}\right)$ are mutually independent.

As risk factors we use the path of the macroeconomic residuals $\boldsymbol{v}=\left(\boldsymbol{v}_{t+1}\right.$, $\left.\boldsymbol{v}_{t+2}, \cdots, \boldsymbol{v}_{t+m}\right)$ for an $m$ period stress testing analysis. By (9) the $\boldsymbol{v}$ determine the macrovariables $\boldsymbol{x}$, and vice versa. The risk factors, over which the objective function takes expectations, are $u_{k, t}$ and $f_{t}$ in (8). So far the general structure of the model.

In our implementation, we take as macrovariables $\boldsymbol{x}_{t}$ the quarterly changes in GDP and the real interest rate $r$ such that

$$
\boldsymbol{x}_{t}=\left[\begin{array}{c}
\left(G D P_{t} / G D P_{t-4}\right)-1 \\
r_{t}
\end{array}\right] \text {. }
$$


The information $I_{t}$ prevailing at time $t$ includes current and past values of the macro variables $\left(\boldsymbol{x}_{t}, \boldsymbol{x}_{t-1}, \ldots\right)$ as well as $\left(z_{k, t}, z_{k, t-1}, \ldots\right)$ for all $k$.

We use the second, third and fourth lags in (8), which seem to be the most significant ones in our application. So $\gamma_{k, j}=0$ for $j=1$ and $j>4$. With this lag-structure the macro factors at time $t$ influence the expected loss only in periods $t+2, t+3$ and $t+4$.

The parameters in (8) and (9) can be estimated separately, since they are Gaussian conditionally independent vector autoregressive models.

\subsection{Worst Case Search on a Plausible Domain}

In our model the risk factors of interest affecting the expected value of the credit portfolio at a future time horizon $t+m$ are the path of macroeconomic shocks, denoted by $\boldsymbol{v}$. These paths describe our scenarios. We compute the expected loss with respect to all other risk factors. The maximum loss over a given set of scenarios $S$ is given by

$$
\operatorname{MaxLoss}_{S}(L):=\max _{\boldsymbol{v} \in S} \mathbb{E}\left[\sum_{s=t+1}^{t+m} \sum_{i} L_{i, t}\left(\boldsymbol{u}_{i}, \boldsymbol{v}\right) \mid I_{t}, \boldsymbol{v}\right],
$$

Maximum loss is a coherent risk measure (Artzner et al. [1999]) for any given feasible risk factor region $S$.

The choice of the region $S$ leads to our concept of plausibility. We define plausibility as a probabilistic concept: The higher the probability to move to a scenario $\boldsymbol{v}$, the higher is its plausibility. This implies that scenarios which are more distant from the expected value of the current scenario, $\boldsymbol{\mu}=\mathbb{E}(\boldsymbol{v})$, will be less plausible. And scenarios which involve a move against the prevailing correlations, $\boldsymbol{\Sigma}=\operatorname{cov}(\boldsymbol{v})$, will be less plausible than scenarios involving a move along with the correlations.

The Mahalanobis distance of $\boldsymbol{v}$ from $\boldsymbol{\mu}$ is defined as

$$
\operatorname{Maha}(\boldsymbol{v}):=\sqrt{(\boldsymbol{\mu}-\boldsymbol{v})^{T} \boldsymbol{\Sigma}^{-1}(\boldsymbol{\mu}-\boldsymbol{v})}
$$

The method can be applied if the second moments of the distribution of $\boldsymbol{v}$ are finite. In case the distribution of $\boldsymbol{v}$ is elliptical the level surfaces of the density function are ellipsoids with constant Mahalanobis distance. ${ }^{1}$ Hence, all the realisations of $\boldsymbol{v}$ with the same Mahalanobis distance are equally likely or equally plausible under ellipticity. Hence, we propose to take as trust regions the ellipsoid of some given Mahalanobis radius $\tau$ :

$$
\operatorname{Ell}_{\tau}:=\{\boldsymbol{v}: \operatorname{Maha}(\boldsymbol{v}) \leq \tau\}
$$

$\tau$ is proportional to the lengths of the main axes of the ellipsoid. For an intuitive interpretation of $\tau$, note that $\mathrm{Ell}_{\tau}$ contains only (but not all) moves in which all risk factors move $\tau$ standard deviations or less. Hence, the higher the value of $\tau$ the less plausible the scenarios will be.

\footnotetext{
${ }^{1}$ Formally, $\boldsymbol{v}$ is elliptical if it can be expressed as the location-scale transform $\boldsymbol{v}=\boldsymbol{\mu}+\boldsymbol{\Sigma}^{1 / 2} \boldsymbol{y}$ of a spherical random vector $\boldsymbol{y}$. $\boldsymbol{y}$ in turn is said to have a spherical distribution if its characteristic function $\psi_{\boldsymbol{y}}(\boldsymbol{t})=E\left[\exp \left(i \boldsymbol{t}^{\prime} \boldsymbol{y}\right)\right]$ can be expressed as a function of the norm of $\boldsymbol{t}$, that is, $\psi_{\boldsymbol{y}}(\boldsymbol{t})=\phi\left(\boldsymbol{t}^{\prime} \boldsymbol{t}\right)$. See Fang et al. [1987] for more details.
} 


\subsection{Methods to Identify Worst Case Scenarios}

Identifying the scenario in the ellipsoid $\mathrm{Ell}_{\tau}$ which leads to the maximum loss is a non-linear optimization problem, which can be computationally demanding. An explicit evaluation of the expected loss requires the computation of a high dimensional Gaussian cdf $\Phi$, which is expensive in terms of CPU time.

As Method 1 we used a Monte Carlo algorithm working in a series of focusation steps on the surface of the ellipsoid, as described in Pistovčák and Breuer [2004]. We used 20 focusation steps with 60 evaluations of the objective function in each step. Worst case search with this approach may be quite slow, since the the maximisation algorithm requires the evaluation of the objective function at 1200 different points.

Method 2 is based on a linear approximation of the loss function. If the loss function were linear, $\boldsymbol{l} \cdot(\boldsymbol{\mu}-\boldsymbol{v})$, and if the risk factor distribution is a multivariate normal, $\boldsymbol{v} \sim N(\boldsymbol{\mu}, \Sigma)$, the worst case scenario could be calculated analytically by

$$
\overline{\boldsymbol{\mu}}=\boldsymbol{\mu}-\frac{\tau}{\sqrt{\boldsymbol{l}^{T} \Sigma \boldsymbol{l}}} \Sigma \boldsymbol{l} .
$$

This is illustrated in Figure 1. From (16) we can see that in the case of a linear loss function the worst case is linear in $\tau$.

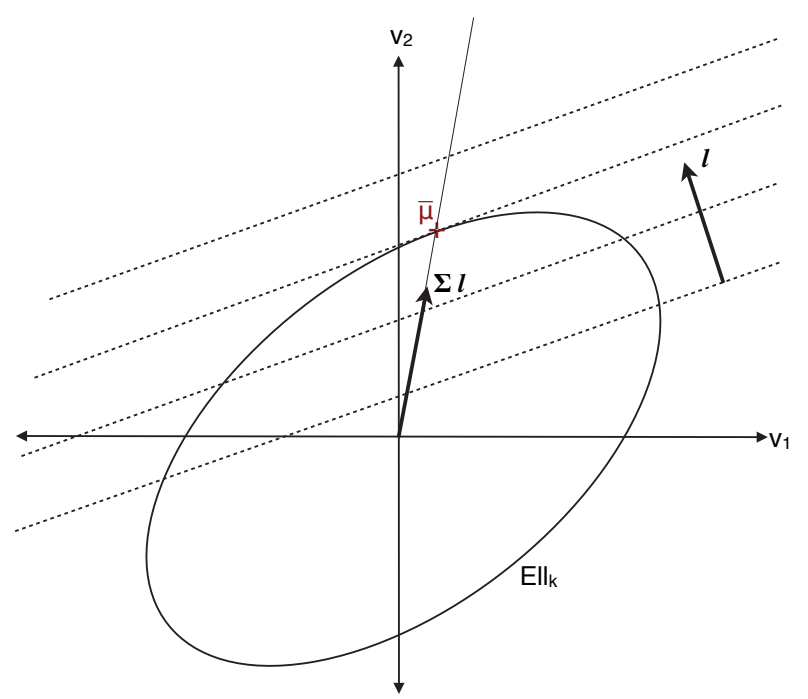

Figure 1: Analytic calculation of the worst case scenario $\overline{\boldsymbol{\mu}}$ for a linear portfolio.

We can compute the value of the objective function (1), resulting from the credit risk model of Jiménez and Mencía [2009], in closed form. This function is not linear, as the plot in Fig. 2 shows.

Method 2 takes as worst case scenario the worst case scenario (16) of the linear approximation, and then calculates the expected loss in this worst case scenario from the full evaluation of the closed form expected loss. For a path of length $m=6$ quarters with 2 risk factors for each quarter, we have a total of 12 risk factors, so the calculation of the linear approximation $\boldsymbol{l}$ requires 13 evaluations of the objective function. This is by a factor of almost 100 less than what we used for Method 1. Another possible method of worst case search 


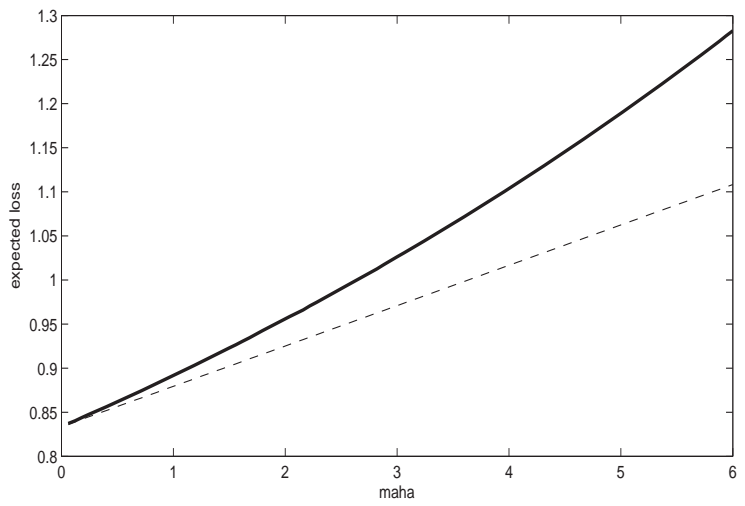

Figure 2: Cumulated expected loss of the portfolio and its linear approximation in the direction of the gradient.

would be to take the worst case scenario of the linear approximation as starting point of the focused Monte Carlo search.

\section{The Data}

As our database we use quarterly series of sectoral default frequencies $p_{k, t}$ from 1984.Q1 to 2006.Q4 from the Spanish central credit register. This credit register contains information about all the loans with volumes higher than $€ 6,000$. Since this threshold is very small, we can safely assume that we are modeling the whole Spanish credit market. We organize the Spanish loan market in its $K=12$ main sectors. LGDs and weights of the sectors are given in Table 1 . These values are consistent with the results of the Fifth Quantitative Impact Survey (QIS5) for the Spanish banking system. We use the actual exposures at default for each loan. 


\begin{tabular}{clcr}
\hline $\mathrm{k}$ & Sector & LGD & weight [\%] \\
\hline 1 & Agriculture & 0.35 & 0.99 \\
2 & Mining & 0.35 & 0.17 \\
3 & Manufacture & 0.35 & 6.25 \\
4 & Utilities & 0.35 & 1.53 \\
5 & Construction & 0.35 & 25.48 \\
6 & Commerces & 0.35 & 4.36 \\
7 & Hotels & 0.35 & 1.63 \\
8 & Communications & 0.35 & 2.40 \\
9 & R\&D & 0.35 & 4.54 \\
10 & Other corporate & 0.35 & 2.13 \\
11 & Mortgages & 0.15 & 37.05 \\
12 & Consumption loans & 0.25 & 13.45 \\
\hline
\end{tabular}

Table 1: Sectors of the Spanish loan market

\begin{tabular}{lccc} 
& Mean $(\%)$ & Std. Dev $(\%)$ & Autocorrelation \\
\hline Agriculture & 1.06 & 0.68 & 0.97 \\
Mining & 0.91 & 0.62 & 0.93 \\
Manufacture & 0.79 & 0.52 & 0.96 \\
Utilities & 0.55 & 0.30 & 0.85 \\
Construction & 1.40 & 1.14 & 0.98 \\
Commerce & 0.79 & 0.54 & 0.97 \\
Hotels & 1.49 & 1.07 & 0.97 \\
Communications & 0.91 & 0.64 & 0.98 \\
R\&D & 0.85 & 0.60 & 0.97 \\
Other corporate & 1.11 & 0.74 & 0.98 \\
Mortgages & 0.52 & 0.46 & 0.97 \\
Consumption loans & 0.66 & 0.37 & 0.97 \\
\hline
\end{tabular}

Table 2: Descriptive statistics of the sectoral default rates 
Table 3: Parameter estimates for evolution (8) of endogenous variables $z_{k}$ in sectors $k . *$ indicates significance at the $90 \%$ level, while $* *$ denotes significance at the $95 \%$ level.

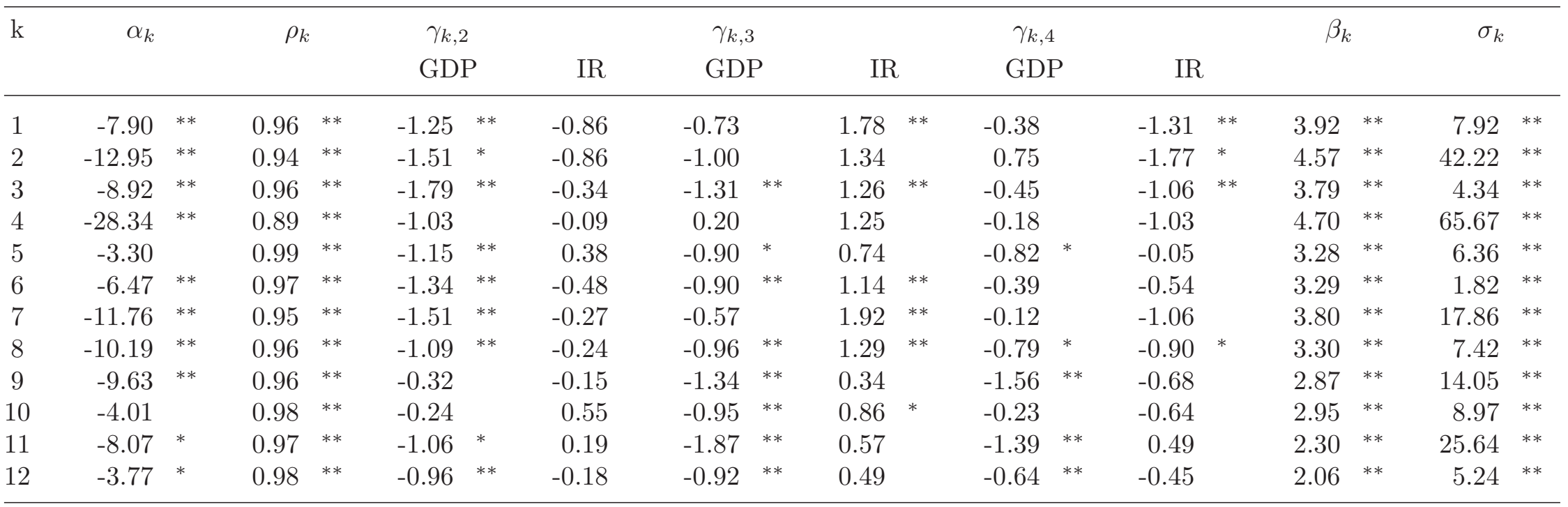

\begin{tabular}{|c|c|c|c|c|}
\hline$A_{0}$ & \multicolumn{2}{|c|}{$A_{1}$} & \multicolumn{2}{|c|}{$\Omega$} \\
\hline 0.02 & $-0.43^{* *}$ & 0.00 & $1.13^{* *}$ & $-0.23^{*}$ \\
\hline 0.03 & 0.00 & $0.38^{* *}$ & $-0.23^{*}$ & $1.18^{* *}$ \\
\hline
\end{tabular}

Table 4: Parameter estimates for the diagonal AR(1) process of macrovariables (9). 
It can be shown that default frequencies $\left(p_{k, t}\right)$ asymptotically tend to default probabilities $\left(\pi_{k, t}\right)$ as the number of loans grows to infinity. Due to the large number of loans per sector in our application, we can safely use $p_{k, t}$ as a proxy of $\pi_{k, t}$. As Fig. 3 shows, probabilities of default are far from being iid as the traditional single factor models assumes. These series tend to be very persistent and highly sensitive to the macroeconomic situation. Not surprisingly, the highest probabilities of default over the sample period are observed during the Spanish recession in 1992-1993. Table 2, which shows the main descriptive statistics of the default frequencies, confirm the high persistence of these series. In order to take into account these features, we consider the multifactor probit model of Jiménez and Mencía to explain the evolution of the probabilities of default as a function of GDP growth and interest rate changes, as well as an additional common latent factor and sector idiosyncratic shocks. Hence, GDP and interest rates capture the sensitivity of the probabilities of default to macroeconomic shocks, while the remaining latent factors capture residual risk, either common or idiosyncratic. Our estimates, shown in Tables 3 and 4, indicate that default rates increase when either GDP growth falls or interest rates rise.

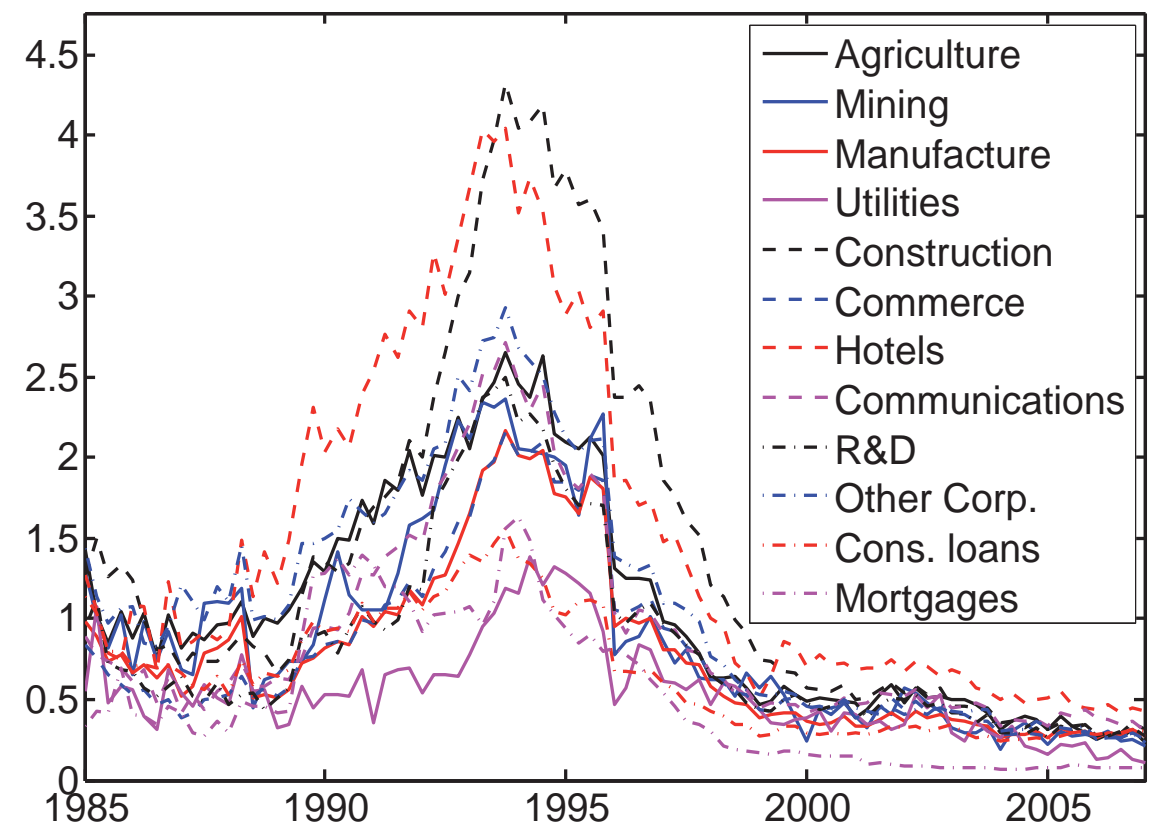

Figure 3: Historical default frequencies in the Spanish economy

\section{Results}

In this section we compare stress testing results from traditional approaches (synthetic standard scenario, historical stress scenario) to worst case scenarios. We consider two stress scenarios consisting of six time steps of three months each. Expected losses are aggregated over eight periods. Because expected losses do not depend on the present value and the first lag of the macroeconomic variables $\left(\gamma_{0}=\gamma_{1}=0\right)$, the expected losses of the first two periods are already 


\begin{tabular}{lrrr}
\hline & GDP $-3 \sigma$ & WCS Method 1 & WCS Method 2 \\
\hline EL increase & $18.11 \%$ & $28.31 \%$ & $29.64 \%$ \\
\hline GDP: Q1 & -3.00 & -1.79 & -1.87 \\
GDP: Q2 & 0.00 & -0.85 & -0.73 \\
GDP: Q3 & 0.00 & -0.75 & -0.85 \\
GDP: Q4 & 0.00 & -0.53 & -0.49 \\
GDP: Q5 & 0.00 & -0.14 & -0.27 \\
GDP: Q6 & 0.00 & -0.18 & -0.07 \\
IR: Q1 & 0.00 & 1.56 & 1.54 \\
IR: Q2 & 0.00 & 1.17 & 1.55 \\
IR: Q3 & 0.00 & 1.05 & 1.37 \\
IR: Q4 & 0.00 & 0.84 & 1.08 \\
IR: Q5 & 0.00 & 1.01 & 0.73 \\
IR: Q6 & 0.00 & 0.64 & 0.35 \\
\hline
\end{tabular}

Table 5: $-3 \sigma$ drop in GDP versus worst case at the same level of plausibility.

Risk factor changes given in standard deviations. Plausibility level $\tau=3.34$.

determined by the past values of the macro variables. Expected losses in periods 7 and 8 are determined by the macro variable values of the six-period scenarios.

\subsection{Worst Case Search Versus a Single Extreme Drop in GDP}

The first standard stress scenario is a synthetic one-step scenario, in which GDP growth decreases by three standard deviations from its mean in the first quarter and returns to its mean during the next quarters. There are no further shocks to GDP growth innovations from quarter 2 onwards until the analysis horizon of $m=8$ quarters. Innovations to interest rates are not shocked either. The plausibility of this scenario can be quantified by a Maha of 3.34. If we take at the same level of plausibility the worst case for the given loan portfolio we see that expected loss increases considerably more than the naive stress test would suggest. While the three standard deviations GDP drop scenario increases expected loss by $18.1 \%$, in the worst case we get an (approximate) increase by $29.6 \%$.

The worst case search reveals that for the given portfolio the worst case differs from the one-period GDP scenario in two important points. First, a simultaneous increase in interest rates amplifies the effects of the GDP drop. The economic reason is that higher interest rates increase the payment obligation of borrowers, which in turn leads to an increase in defaults. The fact that the scenarios really harmful to a loan portfolio involve not just GDP drops but other risk factors as well is in line with the findings of Alfaro and Drehmann [2009] that loan losses caused only by a GDP drop are not able to replicate the dynamics of many past banking crises, and that other risk factors should also play a role. The naive stress test not only underestimate the expected portfolio 
loss but it also neglects a decisive risk factor. Second, the worst case scenario has a slightly less dramatic drop in GDP in the first quarter but further drops in the following quarters. This shows that the multi-period set-up is indeed relevant to understand the dynamics of severe crises. Due to the high persistence of actual default rates and the autoregressive properties of macroeconomic time series a severe crisis is not a one-shot event but unfolds in a number of time steps.

A meaningful stress test needs to be portfolio specific. Different portfolios may show different sensitivity to different risk factors. Macro scenarios that might as such sound very dramatic may for certain portfolios even have a beneficial effect in terms of expected loss. Worst case search takes portfolio specificity fully into account and reveals the decisive risk factors.

Method 2 identifies a slightly more harmful worst case scenario than Method 1 despite the higher computational expenses of the first method.

\subsection{Worst Case Search Versus Extreme Historical Episode}

Historical stress scenarios have the advantage of naturally involving more than one risk factor and more than one time step. Therefore historical scenarios are a popular choice for stress tests. In the following we compare the analysis of a historical episode, the 1992 recession in Spain, to the worst case of the same plausibility. GDP and the interest rate repeat the relative changes of the Spanish crisis from 1992.Q3 to 1993.Q4. The macroeconomic time series with the 1992 crisis and its revival in 2007 are shown in Fig. 4.

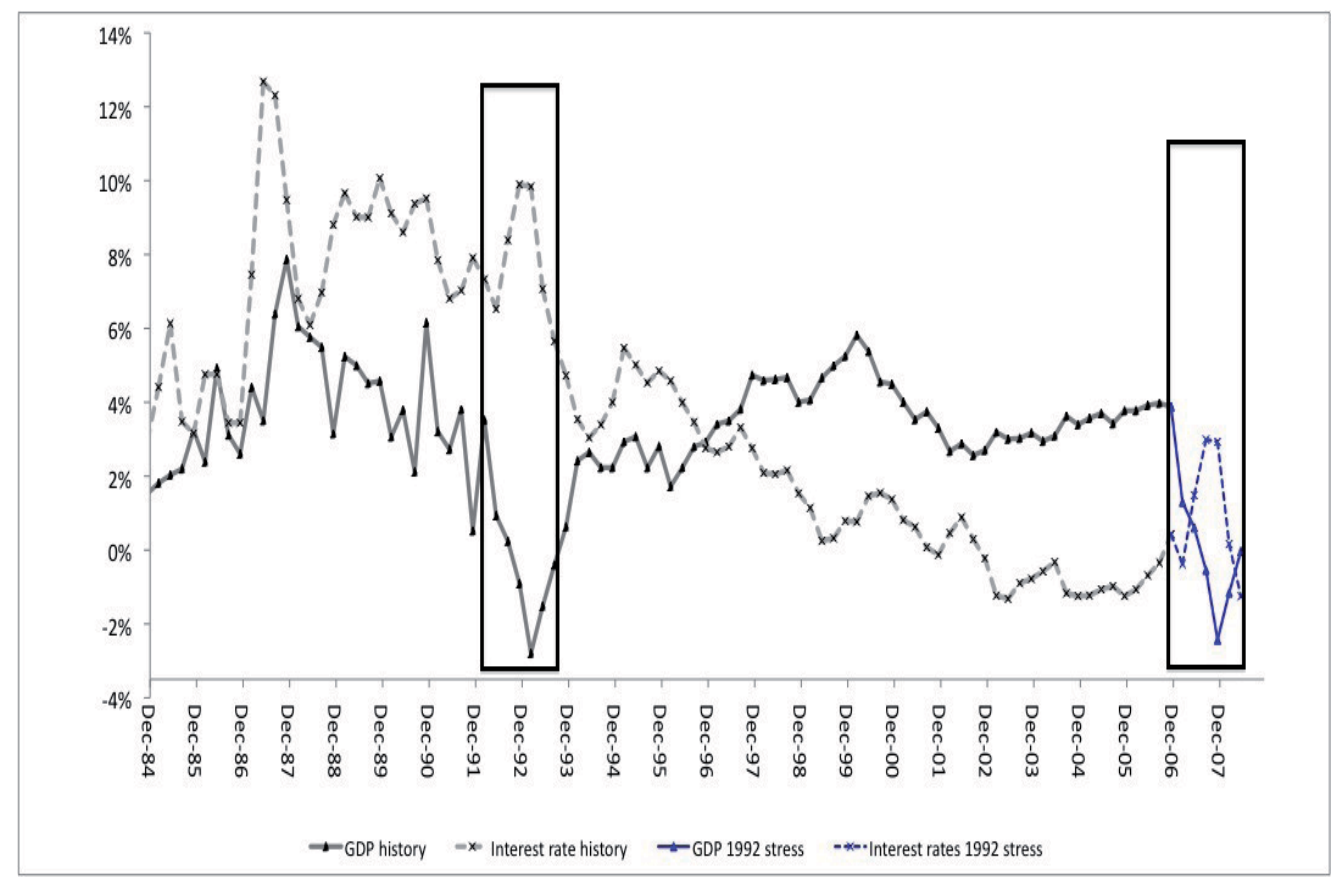

Figure 4: Historical scenario: Revival of the 1992 crisis in 2007.

The plausibility of this scenario can be quantified by a Maha of 5.63. This is more extreme than the scenario described by the previous example. Table 6 gives the results of the worst case search. This time method 2 identifies a scenario 


\begin{tabular}{lrrr}
\hline & 92 crisis revival & WCS Method 1 & WCS Method 2 \\
\hline EL increase & $27.53 \%$ & $55.13 \%$ & $56.91 \%$ \\
\hline GDP: Q1 & -2.58 & -3.19 & -3.19 \\
GDP: Q2 & -0.69 & -1.28 & -1.17 \\
GDP: Q3 & -1.15 & -1.45 & -1.43 \\
GDP: Q4 & -1.89 & -0.80 & -0.82 \\
GDP: Q5 & 1.28 & -0.33 & -0.49 \\
GDP: Q6 & 1.12 & -0.23 & -0.13 \\
IR: Q1 & -0.79 & 2.10 & 2.23 \\
IR: Q2 & 1.86 & 1.86 & 2.53 \\
IR: Q3 & 1.50 & 1.92 & 2.30 \\
IR: Q4 & -0.07 & 1.40 & 1.84 \\
IR: Q5 & -2.78 & 1.67 & 1.23 \\
IR: Q6 & -1.41 & 0.81 & 0.55 \\
\hline
\end{tabular}

Table 6: 1992 crisis versus worst case at the same level of plausibility. Risk factor changes given in standard deviations. Plausibility level $\tau=5.63$.

with higher expected losses than Method 1. Apparently the optimization errors involved in Method 1 are worse than the approximation errors of Method 2.

The worst case at the same level of plausibility is an expected loss increase of $56.9 \%$ instead of the $27.5 \%$ increase produced by the historical scenario. There are two main reasons for the difference. First, the worst case scenario involves a rise in interest rates persisting over the full eight quarters of our analysis, whereas the historical scenario involves a clear rise of interest rates only in the second and third quarter. Second, the historical scenario involves a sharp drop in GDP and a subsequent rise, whereas in the worst case the GDP drop is less sharp but persists for a longer time.

This reflects a well-known problem of stress tests with historical scenarios. Risk factor movements in a historical crisis are just one possible course of events. Other scenarios might be equally plausible but much more harmful for the portfolio. The next crisis need not be, and probably will not be, exactly like a past crisis. 'History doesn't repeat itself, at best rhymes sometimes', is a saying attributed to Mark Twain. Using worst case search we can be sure that at the chosen level of plausibility we have indeed captured the most detrimental scenario, irrespective of whether or not it happened in history.

The stress tests were performed from the point of view as of January 2007, using only data up to December 2006. At that time the Spanish economy was in its heyday with no sign of the 2008/09 crisis. The stress scenarios can be compared to what happened in reality after January 2007, see Fig. 5. The scenario realised from 2007.Q1 to 2008.Q2 has a Maha of 2.03, and it produces a $3.37 \%$ increase of expected loss according to our model. So the realised scenario is more plausible and less harmful than both the 1992 crisis revival and the worst case scenario.

How well does our method gauge the economic crisis of 2008-09, of which 


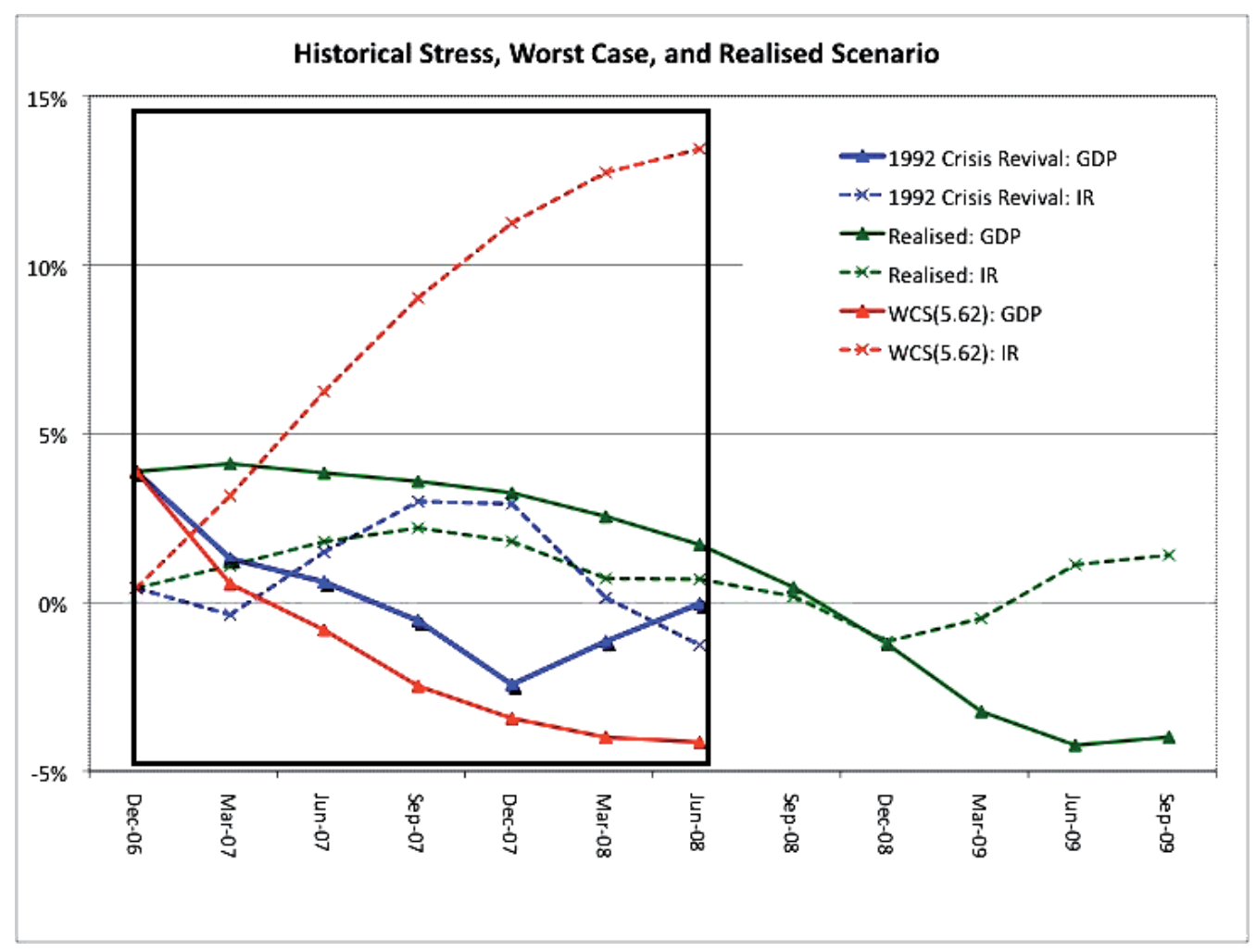

Figure 5: Comparison of the 1992 Crisis revival, the worst case scenario of the same plausibility, and the realised scenario.

there was no indication at the time the stress tests were performed? Fig. 5 also shows that the crisis did not hit Spanish GDP until Summer 2008. The scenario realised from 2008.Q1 until 2009.Q3 displays a similar GDP evolution as the worst case scenario envisaged in January 2007. It has plausibility of 4.88 and model-implied expected loss increase of $47 \%$. This scenario is almost as extreme as the worst case scenario at $\tau=5.62$ from the point of view of January 2007, and it leads to a comparable increase in expected loss (47\% vs. $56 \%$ ) The worst case scenario determined with our method with data up to January 2007 gives a reasonable good gauge of the crisis to come.

Knowledge of the worst case scenario suggests risk reducing actions. The characteristic risk factor movements in the worst case scenarios are a drop in GDP and simultaneous increase in interest rates. An institution wishing to reduce loss in the worst case scenarios will take positions which are profitable under the worst case moves of the risk factors. For example, it might buy options paying off in case of interest rate increases. But there are two caveats: First, one must not overlook the default risk of the option writer. If the option writer is exposed to similar risk as the institution seeking to insure losses, he might default when the insurance taker needs him most. Second, some risk factors, as for example GDP, are hard to insure on a large scale. Probably it is difficult to find a counterparty willing and able to pay amounts comparable to the losses of the Spanish loan portfolio in case of a GDP drop.

Alternatively, institutions might try to reduce their exposures to those sectors that are more sensitive to the worst case scenario. In this sense, Table 7 shows that some sectors, such as Mining and Utilities, remain largely unaffected by worst case scenario. (These sectors have their own worst case scenarios, but these are very different from the economy's worst case scenario.) In contrast, 


\begin{tabular}{lcc}
\hline Sector & WCS Method 1 & WCS Method 2 \\
\hline Agriculture & 31.27 & 30.10 \\
Mining & 7.88 & 6.13 \\
Manufacture & 59.17 & 58.45 \\
Utilities & 7.71 & 7.85 \\
Construction & 67.88 & 71.83 \\
Commerce & 43.79 & 43.83 \\
Hotels & 39.76 & 41.49 \\
Communication & 45.88 & 46.28 \\
R\&D & 34.03 & 32.20 \\
Other Corporate & 38.44 & 41.42 \\
Mortgages & 97.71 & 102.21 \\
Consumption loans & 35.26 & 34.50 \\
\hline Total & 55.13 & 56.91 \\
\hline
\end{tabular}

Table 7: Sectoral changes of expected losses in the worst case (\%). Plausibility level $\tau=5.63$.

the sectors Construction and Mortgages yield the highest changes in expected losses. These are the sectors suffering particularly hard in the worst case scenario of the economy. (The worst case scenarios of these sectors are similar to the economy's worst case scenario.) Hence, institutions may either reduce the risks of their loan portfolios by avoiding an excessive concentration on the riskiest types of loans, or adjust their levels of capital in order to cover the potential losses in the worst case scenario.

\section{Conclusion}

In this paper we developed a systematic approach to multi-period macro stress tests of loan portfolios. We have shown that the requirements of using scenarios that are extreme yet plausible can be made precise: We define plausibility as the number of (multivariate) standard deviations the stress scenario is away from an average scenario. In this region of plausibility the worst case for the portfolio analysed can be determined by maximizing expected loss.

Compared to standard ways of constructing scenarios in stress testing by thought experiments or historical reference scenarios this approach has several advantages. First it makes transparent the plausibility of the scenario considered. Second, it makes sure that in the context of the model one finds indeed the most adverse scenario for the given portfolio and that we do not forget a detrimental scenario at a given level of plausibility. Third because the method takes into account the portfolio specificity of the worst case scenario it immediately suggests risk reducing actions and therefore gives a clear picture of the risk situation. Furthermore we see in our example that when applied to data up to December 2006, which does not include information from the crisis, our method outperforms traditional approaches in gauging the recent crisis. From a practical perspective, we propose a linear approximation to compute the worst 
case scenario analytically. This linearisation does not only work extremely well in terms of accuracy, but it also substantially reduces the CPU time required by the full blown worst case search.

To add the method to the existing arsenal of stress testing methods is easy because it is compatible with many models of portfolio credit risk used among stress testing practitioners. It is thus compatible with stress testing technology already in place. In many cases a linear approximation of expected loss will be reasonably accurate. In these cases worst case search is very fast and computationally highly efficient. But our method has another advantage in terms of the political economy of stress testing. By making stress scenario construction systematic and by entering the major input of judgment to the question of determining plausibility of stress scenarios our approach is more manipulation proof than traditional procedures. We believe that this aspect is practically of high relevance and importance if stress testing should be credible and useful.

We hope that these conceptual advantages in combination with the straightforward and efficient way in which the method can be applied might persuade some practitioners of stress testing to add worst case search to their methodological arsenal and support the profession in the search of a more systematic approach to the construction of stress scenarios. 


\section{References}

R. Alfaro and M. Drehmann. Macro stress tests and crises: what can we learn? In BIS Quarterly Review, pages 29-41. Bank of International Settlements, December 2009.

P. Artzner, F. Delbaen, J. Ebner, and D. Heath. Coherent measures of risk. Mathematical Finance, 9:203-228, 1999.

F. Black and M. Scholes. The pricing of options and corporate liabilities. Journal of Political Economy, 81:637-655, 1973.

C. Borio and M. Drehmann. Towards an operational framework for financial stability: 'fuzzy' measurement and its consequences. BIS Working Paper 284, Bank of International Settlements, 2009.

T. Breuer and I. Csiszár. If worse comes to worst: Systematic stress testing in general risk models. eLibrary 1328022, SSRN, 2010. URL http://ssrn. com/paper $=1328022$.

T. Breuer, M. Jandačka, K. Rheinberger, and M. Summer. How to find plausible, severe and useful stress scenarios. International Journal of Central Banking, 3:205-224, 2009.

M. Drehmann. A market based macro stress test for the corporate credit exposures of UK banks. Bank of England Working Paper, 2005.

M. Drehmann, A. J. Patton, and S. Sorensen. Corporate defaults and macroeconomic shocks: non-linearities and uncertainty. Bank of England Working Paper. 2006.

Kai-Tai Fang, Samuel Kotz, and Kai-Wang Ng. Symmetric Multivariate and Related Distributions, volume 36 of Monographs in Statistics and Probability. Chapman and Hall, London, 1987.

C. Finger. Conditional approaches for CreditMetrics portfolio distributions. CreditMetrics Monitor, Riskmetrics Group, 1999.

R. Fiori, A. Foglia, and S. Iannotti. Estimating macroeconomic credit risk and sectoral default rate correlations for the italian economy. Bank of Italy Working Paper, 2007.

M. B. Gordy. A risk-factor model foundation for ratings-based bank capital rules. Journal of Financial Intermediation, 12:199-232, 2003.

G. Jiménez and J. Mencía. Modeling the distribution of credit losses with observable and latent factors. Journal of Empirical Finance, 16:235-253, 2009 .

R. C. Merton. On the pricing of corporate debt: The risk structure of interest rates. Journal of Finance, 29:449-470, 1974.

M. Misina, D. Tessier, and S. Dey. Stress testing the corporate loans portfolio of the Canadian banking sector. Bank of Canada Working Paper No. 2006-47, 2006 . 
M. H. Pesaran, T. Schuermann, B. J. Treutler, and S. M. Weiner. Macroeconomic dynamics and credit risk: a global perspective. Journal of Money, Credit and Banking, 38:1211-1261, 2006.

F. Pistovčák and T. Breuer. Using Quasi Monte Carlo-Scenarios in risk management. In Harald Niederreiter, editor, Monte Carlo and Quasi-Monte CarloMethods 2002, pages 379-392. Springer, 2004.

O. Vasicek. Probability of loss on loan portfolio. Technical report, KMV Corporation, 1987.

K. Virolainen. Macro stress testing with a macroeconomic credit risk model for Finland. Bank of Finland discussion paper No. 18, 2004.

T. C. Wilson. Portfolio credit risk (I). Risk, 10:56-61, 1997a.

T. C. Wilson. Portfolio credit risk (II). Risk, 10:111-117, $1997 \mathrm{~b}$.

J. H. Y. Wong, K. F. Choi, and P. W. Fong. A framework for stress-testing banks' credit risk. Journal of Risk Model Validation, 2:3-23, 2008. 


\title{
BANCO DE ESPAÑA PUBLICATIONS
}

\author{
WORKING PAPERS
}

0901 PRAVEEN KUJAL AND JUAN RUIZ: International trade policy towards monopoly and oligopoly

0902 CATIA BATISTA, AITOR LACUESTA AND PEDRO VICENTE: Micro evidence of the brain gain hypothesis: The case of Cape Verde.

0903 MARGARITA RUBIO: Fixed and variable-rate mortgages, business cycles and monetary policy.

0904 MARIO IZQUIERDO, AITOR LACUESTA AND RAQUEL VEGAS: Assimilation of immigrants in Spain: A longitudinal analysis.

0905 ÁNGEL ESTRADA: The mark-ups in the Spanish economy: international comparison and recent evolution.

0906 RICARDO GIMENO AND JOSÉ MANUEL MARQUÉS: Extraction of financial market expectations about inflation and interest rates from a liquid market.

0907 LAURA HOSPIDO: Job changes and individual-job specific wage dynamics.

0908 M. ${ }^{a}$ DE LOS LLANOS MATEA AND JUAN S. MORA-SANGUINETTI: Developments in retail trade regulation in Spain and their macroeconomic implications. (The original Spanish version has the same number.)

0909 JAVIER MENCÍA AND ENRIQUE SENTANA: Multivariate location-scale mixtures of normals and mean-varianceskewness portfolio allocation.

0910 ALICIA GARCÍA-HERRERO, SERGIO GAVILÁ AND DANIEL SANTABÁRBARA: What explains the low profitability of Chinese banks?

0911 JAVIER MENCÍA: Assessing the risk-return trade-off in loans portfolios.

0912 MAXIMO CAMACHO AND GABRIEL PEREZ-QUIROS: Ñ-STING: España Short Term Indicator of Growth.

0913 RAQUEL VEGAS, ISABEL ARGIMÓN, MARTA BOTELLA AND CLARA I. GONZÁLEZ: Retirement behaviour and retirement incentives in Spain.

0914 FEDERICO CINGANO, MARCO LEONARDI, JULIÁN MESSINA AND GIOVANNI PICA: The effect of employment protection legislation and financial market imperfections on investment: Evidence from a firm-level panel of EU countries.

0915 JOSÉ MANUEL CAMPA AND IGNACIO HERNANDO: Cash, access to credit, and value creation in M\&As.

0916 MARGARITA RUBIO: Housing market heterogeneity in a monetary union.

0917 MAXIMO CAMACHO, GABRIEL PEREZ-QUIROS AND HUGO RODRÍGUEZ MENDIZÁBAL: High-growth Recoveries, Inventories and the Great Moderation.

0918 KAI CHRISTOFFEL, JAMES COSTAIN, GREGORY DE WALQUE, KEITH KUESTER, TOBIAS LINZERT, STEPHEN MILLARD AND OLIVIER PIERRARD: Wage, inflation and employment dynamics with labour market matching.

0919 JESÚS VÁZQUEZ, RAMÓN MARÍA-DOLORES AND JUAN-MIGUEL LONDOÑO: On the informational role of term structure in the U.S. monetary policy rule.

0920 PALOMA LÓPEZ-GARCÍA AND SERGIO PUENTE: What makes a high-growth firm? A probit analysis using Spanish firm-level data.

0921 FABIO CANOVA, MATTEO CICCARELLI AND EVA ORTEGA: Do institutional changes affect business cycles? Evidence from Europe.

0922 GALO NUÑO: Technology, convergence and business cycles.

0923 FRANCISCO DE CASTRO AND JOSÉ LUIS FERNÁNDEZ: The relationship between public and private saving in Spain: does Ricardian equivalence hold?

0924 GONZALO FERNÁNDEZ-DE-CÓRDOBA, JAVIER J. PÉREZ AND JOSÉ L. TORRES: Public and private sector wages interactions in a general equilibrium model.

0925 ÁNGEL ESTRADA AND JOSÉ MANUEL MONTERO: R\&D investment and endogenous growth: a SVAR approach.

0926 JUANA ALEDO, FERNANDO GARCÍA-MARTÍNEZ AND JUAN M. MARÍN DIAZARAQUE: Firm-specific factors influencing the selection of accounting options provided by the IFRS: Empirical evidence from Spanish market.

0927 JAVIER ANDRÉS, SAMUEL HURTADO, EVA ORTEGA AND CARLOS THOMAS: Spain in the euro: a general equilibrium analysis.

0928 MAX GILLMAN AND ANTON NAKOV: Monetary effects on nominal oil prices.

0929 JAVIER MENCÍA AND ENRIQUE SENTANA: Distributional tests in multivariate dynamic models with Normal and Student $t$ innovations.

0930 JOAN PAREDES, PABLO BURRIEL, FRANCISCO DE CASTRO, DANIEL GARROTE, ESTHER GORDO AND JAVIER J. PÉREZ: Fiscal policy shocks in the euro area and the US: an empirical assessment.

1. Previously published Working Papers are listed in the Banco de España publications catalogue. 
0931 TERESA LEAL, DIEGO J. PEDREGAL AND JAVIER J. PÉREZ: Short-term monitoring of the Spanish Government balance with mixed-frequencies models.

0932 ANTON NAKOV AND GALO NUÑO: Oilgopoly: a general equilibrium model of the oil-macroeconomy nexus.

0933 TERESA LEAL AND JAVIER J. PÉREZ: Análisis de las desviaciones presupuestarias aplicado al caso del presupuesto del Estado.

0934 JAVIER J. PÉREZ AND A. JESÚS SÁNCHEZ: Is there a signalling role for public wages? Evidence for the euro area based on macro data.

0935 JOAN PAREDES, DIEGO J. PEDREGAL AND JAVIER J. PÉREZ: A quarterly fiscal database for the euro area based on intra-annual fiscal information.

1001 JAVIER ANDRÉS, ÓSCAR ARCE AND CARLOS THOMAS: Banking competition, collateral constraints and optimal monetary policy.

1002 CRISTINA BARCELÓ AND ERNESTO VILLANUEVA: The response of household wealth to the risk of losing the job: evidence from differences in firing costs.

1003 ALEXANDER KARAIVANOV, SONIA RUANO, JESÚS SAURINA AND ROBERT TOWNSEND: No bank, one bank, several banks: does it matter for investment?

1004 GABRIEL PEREZ-QUIROS AND HUGO RODRÍGUEZ MENDIZÁBAL: Asymmetric standing facilities: an unexploited monetary policy tool.

1005 GABRIEL JIMÉNEZ, JOSE A. LOPEZ AND JESÚS SAURINA: How does competition impact bank risk-taking?

1006 GIUSEPPE BERTOLA, AURELIJUS DABUSINSKAS, MARCO HOEBERICHTS, MARIO IZQUIERDO, CLAUDIA KWAPIL, JEREMI MONTORNĖS AND DANIEL RADOWSKI: Price, wage and employment response to shocks: evidence from the WDN Survey.

1007 JAVIER MENCÍA: Testing non-linear dependence in the Hedge Fund industry.

1008 ALFREDO MARTÍN-OLIVER: From proximity to distant banking: Spanish banks in the EMU.

1009 GALO NUÑO: Optimal research and development expenditure: a general equilibrium approach.

1010 LUIS J. ÁLVAREZ AND PABLO BURRIEL: Is a Calvo price setting model consistent with micro price data?

1011 JENS HAGENDORFF, IGNACIO HERNANDO, MARÍA J. NIETO AND LARRY D. WALL: What do premiums paid for bank M\&As reflect? The case of the European Union.

1012 DAVID DE ANTONIO LIEDO: General equilibrium restrictions for dynamic factor models.

1013 JAMES COSTAIN, JUAN F. JIMENO AND CARLOS THOMAS: Employment fluctuations in a dual labor market.

1014 LUIS M. VICEIRA Y RICARDO GIMENO: The euro as a reserve currency for global investors.

1015 PALOMA LÓPEZ-GARCÍA AND JOSÉ MANUEL MONTERO: Understanding the Spanish business Innovation gap: The role of spillovers and firms' absorptive capacity.

1016 AITOR LACUESTA AND SERGIO PUENTE: El efecto del ciclo económico en las entradas y salidas de inmigrantes en España.

1017 REBEKKA CHRISTOPOULOU, JUAN F. JIMENO AND ANA LAMO: Changes in the wage structure in EU countries.

1018 THOMAS BREUER, MARTIN JANDAČKA, JAVIER MENCÍA AND MARTIN SUMMER: A systematic approach to multi-period stress testing of portfolio credit risk.

\section{BANCODEESPAÑA}

Eurosistema
Unidad de Publicaciones

Alcalá, 522; 28027 Madrid

Telephone +34 91338 6363. Fax +34919986488

E-mail: publicaciones@bde.es www.bde.es 